\title{
Tubercles Effect on a Wing Performance for NACA
}

\section{4-421 Aerofoil}

\author{
Gracio Joyal Lobo ${ }^{1}$ \\ Dept. of Aerospace \\ IIAEM - Jain University \\ Bengaluru, India
}

\author{
Amrutha $\mathrm{K}^{2}$ \\ Dept. of Aerospace \\ IIAEM - Jain University \\ Bengaluru, India
}

\author{
Dumpeti Vineeth ${ }^{3}$ \\ Dept. of Aerospace \\ IIAEM - Jain University \\ Bengaluru, India
}

\author{
Medisetti Swami Charan ${ }^{4}$ \\ Dept. of Aerospace \\ IIAEM - Jain University \\ Bengaluru, India
}

\begin{abstract}
Humpback whales have a morphological structure on the leading edge of their flippers that provide them with the capability of extreme manoeuvrability. Inspired by nature, tubercle design has been incorporated in wing-like structures such as wind turbines, marine propellers, etc. The idea of tubercles was studied by P Watts and F E Fish to develop their turbine blades and showed that wind farms can produce up to $20 \%$ more power with less wind.

The purpose of this study was to see how the performance of a finite wing is affected due to the geometrical modification. To understand the effect of tubercles, various parameters are being measured and compared. A Baseline model and model with Tubercles are being tested with a 6 - digit NACA 634-421 cambered airfoil, similar to that of the flipper of the Humpback Whale. Tubercles of various wavelength and amplitudes are taken to analyse and study various aerodynamic characteristics.

Preliminary analysis was carried out in XFLR for baseline model, modeling and computation using ANSYS ICEM CFD and ANSYS CFX respectively. Also, prototypes manufactured using 3-axis CNC Router are tested in the Subsonic Wind Tunnel. The computational data and experimental results are observed in both the cases and the potential advantages and disadvantages of having tubercles on the leading edge of a wing have been noted.
\end{abstract}

Keywords: Morphology, Flippers, Tubercles, Airfoil, CFD, Aerospace, Aerodynamics

\section{INTRODUCTION}

Humpback whale flippers are exceptional in many ways, which includes their curved planform, large aspect ratio especially when compared with other whale species, they also display leading edge tubercles, essentially leading edge bumps facing into the free stream flow, that alter the fluid flow over these flippers. Tubercles could be functional adaptations, thereby imparting an advantage in manoeuvrability and prey capture.

Previous studies carried out by researchers showed that separation is delayed, increasing the maximum attainable lift and maximum stall angle. However, some researchers had also observed that in certain circumstances tubercles cause deterioration in performance at angle of attack before stall. Despite this fact, these cases showed that there were still advantages from incorporating tubercles such as softer stall characteristics and higher post-stall lift.

\subsection{Tubercles}

Tubercles are sinusoidal structures that are present in the leading edge of humpback whale flipper. Leading edge tubercles are widely postulated as a form of passive flow control device for aerodynamic surfaces. Efforts in incorporating these tubercles onto aircraft propeller blades/wings and how tubercles presence effects the original propeller blade flow behaviour are relatively less well understood.

The use of tubercles as a flow control strategy in aerofoils / wings was motivated by observations first made by Fish and Battle on the movements of humpback whales. Humpback whales can grow up to 36 tons on an average, but have high manoeuvrability. The ability to change their direction quickly is attributed to the presence of tubercles in the ends of the flippers.

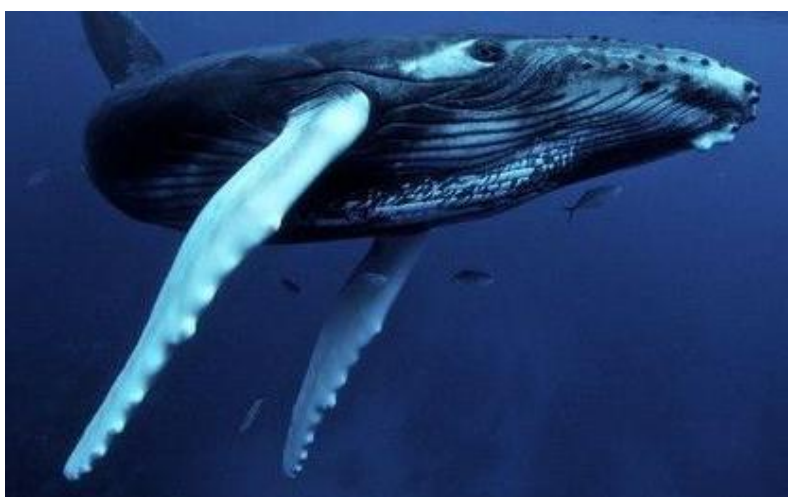

Figure 1: Humpback Whales with Tubercles on their flippers

\section{AIRFOIL SELECTION}

Previous studies were focused on comparing the performance of wing with tubercles having different combinations of wavelength and amplitude. However, only a limited number of tubercle configurations were investigated and the experiments were carried out on wings with the same profile shape. Hence, it was observed that there was still an opportunity to carry out a more detailed investigation into the effects of changing the amplitude and wavelength parameters of tubercles. Also, a comparison between NACA 634-421 airfoil profile shape with and without tubercles have not been made before the current study. Generally, previous studies used symmetric airfoils. Therefore, there was an opportunity 
to investigate an alternative profile shape i.e. cambered airfoil which resembles to the Humpback whale flipper.

The length of flippers of the humpback whale varies from 0.25 to 0.33 percent of total body length. The flippers are highly mobile at the shoulder and exhibit some flexibility along their span, especially when compared with other species of whale. The flippers have high aspect ratio and its crosssection closely resembles the $21 \%$ thick, low drag, NACA 634-021 airfoil. Since there were many previous studies carried out on NACA 634-021 airfoil and very few studies were done to see the effect of tubercles on a cambered airfoil, we decided to study the effect of tubercles on NACA 634-421.

\subsection{Tubercles Size \& Spacing}

Based on the Humpback whales average tubercle size and spacing, there needed to be a range of possibilities while maintain a reasonable scope. From the studies carried out by some of the biologists, it was noted that the number of tubercles typically ranges from 9 to 11 with Maximum and Minimum Aspect Ratios of 7.7 and 3.6, respectively.

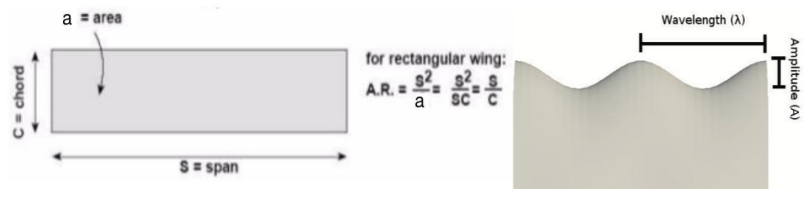

Figure 2: Relation between Span, Chord and Aspect Ratio and figure representing tubercle wavelength and amplitude

Considering the complexity in fabricating a full scale wing model, the Aspect Ratio was chosen to be 3.6. The maximum attainable span length was $580 \mathrm{~mm}$ which was governed by the test section dimensions $(600 \mathrm{~mm} \times 600 \mathrm{~mm} \times 2000 \mathrm{~mm})$. We obtained the chord length to be $161 \mathrm{~mm}$. The tubercles are $10 \%$ to $20 \%$ of the local Chord (Amplitude) and each is about $10 \%$ and $20 \%$ of Span (Wavelength).

Table 1: Considerations effecting chord length selection

\begin{tabular}{|c|c|c|}
\hline Increasing & Reynolds Number increases & Desirable \\
\cline { 2 - 3 } Chord Length & Aspect Ratio decreases & Undesirable \\
\hline
\end{tabular}

A large Reynolds number was desirable, the analysis was carried out for Reynolds number having velocity around 20 $\mathrm{m} / \mathrm{s}$. Also, the aspect ratios, that were used by previous groups in this area of research were also considered.

Table 2: Tubercles Distribution

\begin{tabular}{|c|c|c|c|c|}
\hline \multicolumn{5}{|c|}{ Tubercle Distribution $(\mathrm{C}=0.161 \mathrm{~m} \& \mathrm{~S}=0.580 \mathrm{~m})$} \\
\hline Wavelength & $(\mathrm{mm})$ & Amplitude & $(\mathrm{mm})$ & Model Name \\
\hline \multirow{3}{*}{$\begin{array}{c}10 \% \text { of } \\
\text { Span }\end{array}$} & \multirow{3}{*}{58} & $10 \%$ of Chord & 16.00 & $\lambda 58 \mathrm{~A} 16$ \\
\hline & & $15 \%$ of Chord & 24.15 & $\lambda 58 \mathrm{~A} 24$ \\
\hline & & $20 \%$ of Chord & 32.20 & $\lambda 58 \mathrm{~A} 32$ \\
\hline \multirow{3}{*}{$\begin{array}{c}20 \% \text { of } \\
\text { Span }\end{array}$} & \multirow{3}{*}{116} & $10 \%$ of Chord & 16.00 & $\lambda 116 \mathrm{~A} 16$ \\
\hline & & $15 \%$ of Chord & 24.15 & $\lambda 116 \mathrm{~A} 24$ \\
\hline & & $20 \%$ of Chord & 32.20 & $\lambda 116 \mathrm{~A} 32$ \\
\hline
\end{tabular}

\subsection{Wing Modeling}

Baseline model and tubercles model were modeled using CATIA V5. Two-dimensional profile was imported to Generative Shape Design. Further, according to the required Amplitude and Wavelength, the profiles were protruded which followed the path of a sinusoidal wave at the leading edge. Whereas, the trailing edge section of the aerofoils was kept the same throughout. The tubercles models are modeled in such a way that the planform area is same as that of the baseline model i.e., $\mathrm{a}=0.093 \mathrm{~m}^{2}$.

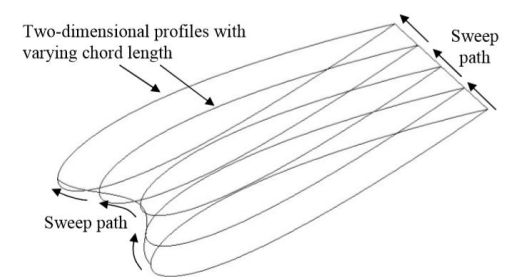

Figure 3: Process used to construct wing models with Tubercles
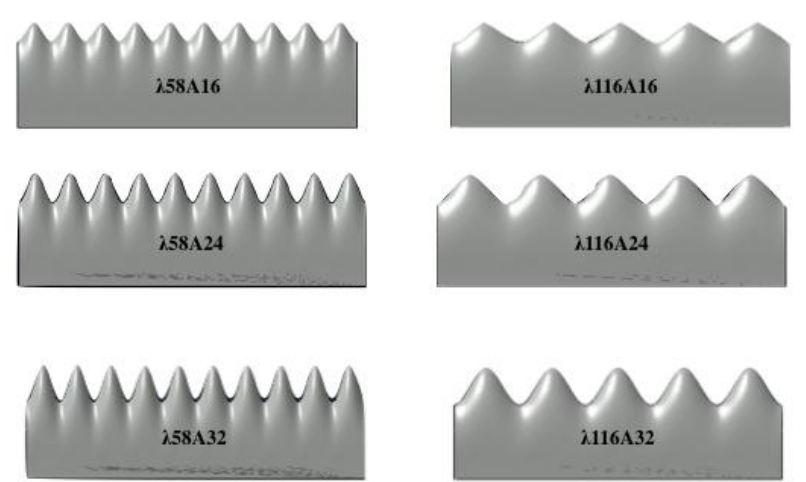

Figure 4: Tubercle Models of various Wavelengths and Amplitudes

\section{NUMERICAL ANALYSIS}

Preliminary analysis was carried out in XFLR for baseline model. Meshing and Numerical Analysis were carried out in ANSYS ICEM CFD and ANSYS CFX respectively. These are industry grade software's which were used for meshing and analysis.

\subsection{Meshing using ANSYS ICEM CFD}

Wing model is imported as a STEP/IGES file to ANSYS ICEM CFD and domain is created that represents a control volume. In our case, a project needs to be created to analyse flow over a wing. Hence, a domain is created to specify the direction of the fluid flow. The far field distance is kept at 8c behind and 7c in front, top and bottom. Here the value of ' $c$ ' is the mean aerodynamic chord.

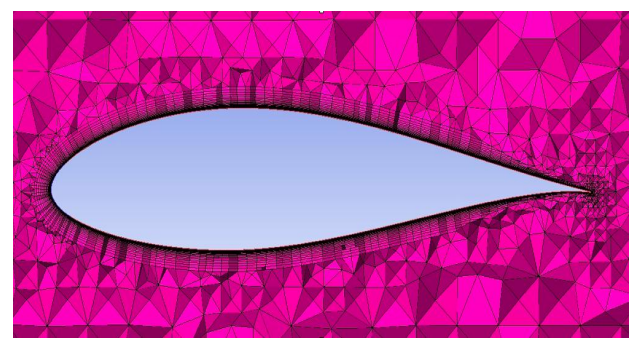

Figure 5: Cross sectional view of Prism mesh around the wing 


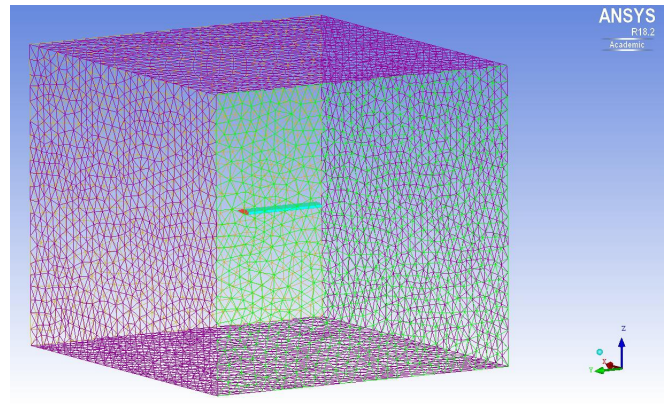

Figure 6: Mesh over the domain and wing

\subsection{Numerical Analysis using ANSYS CFX}

To solve this problem, Shear Stress Transport (SST) model of Menter was used. This model solves a turbulence/frequencybased model $(\mathrm{k}-\omega)$ at the wall and $\mathrm{k}-\varepsilon$ in the bulk flow region. Preliminary analysis was carried out for all tubercle models shown in Figure 4. From the preliminary results it was observed that models $\lambda 58 \mathrm{~A} 16$ and $\lambda 116 \mathrm{~A} 16$ had better lift and drag coefficients when compared to all the other models with tubercles. Hence, models other than $258 \mathrm{~A} 16$ and $\lambda 116 \mathrm{~A} 16$ were eliminated. Further, numerical analysis and experimental analysis was carried out for Baseline model, $\lambda 58 \mathrm{~A} 16$ and $\lambda 116$ A16.

Solution convergence could be monitored through residuals and ensuring that the Lift and Drag values were stagnated. For all the cases the final Lift and Drag values were noted. The stagnated ones with each case took about 500 iterations to converge with computational time of 4 hours.

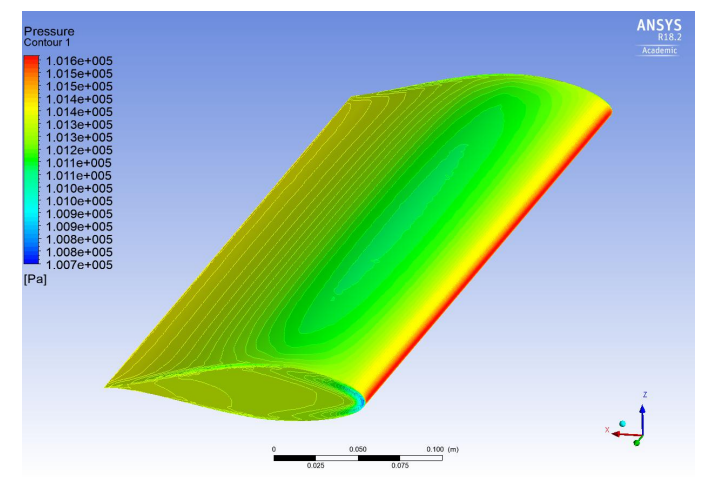

Figure 7: Pressure Distribution over Baseline Model

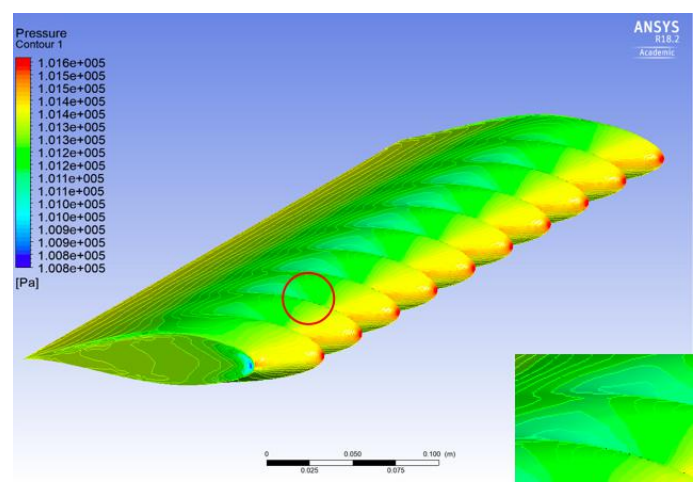

Figure 8: Pressure Distribution over $258 \mathrm{~A} 16$ Model

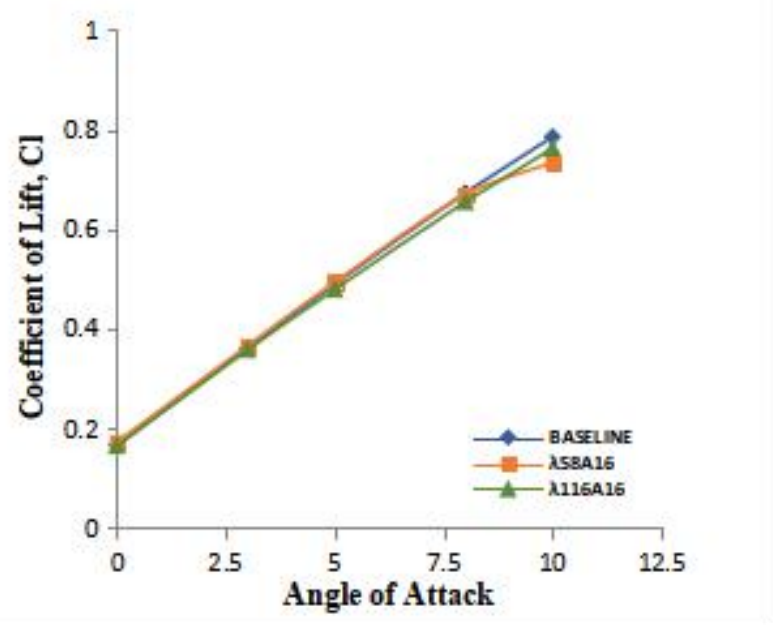

Figure 9: Comparison of $\mathrm{C}_{1}$ vs Alpha from CFD Data

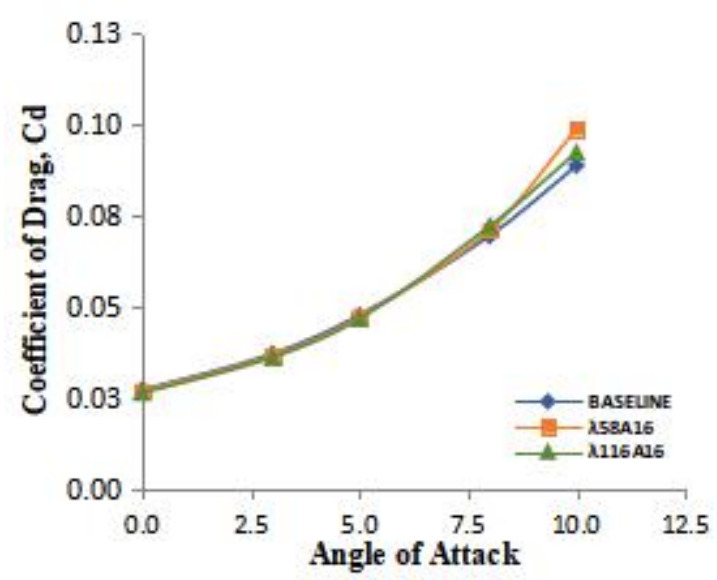

Figure 10: Comparison of $C_{d}$ vs Alpha from CFD Data

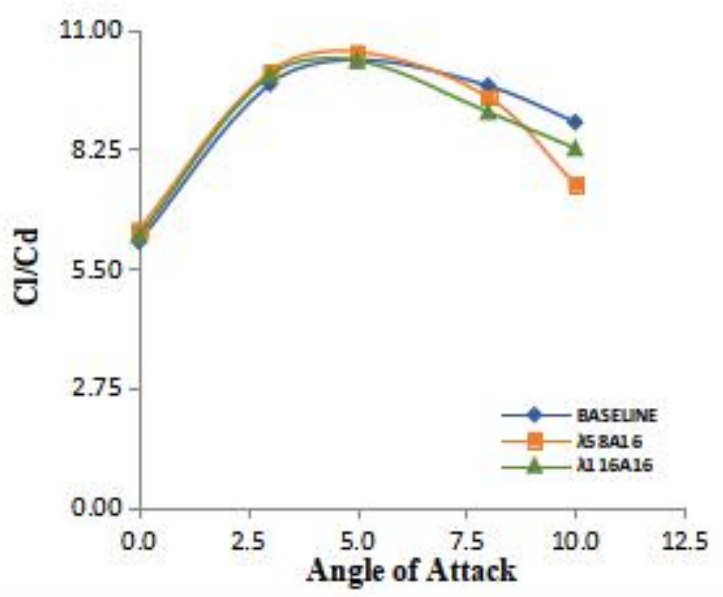

Figure 11: Comparison of $\mathrm{C}_{1} / \mathrm{C}_{\mathrm{d}}$ vs Alpha from CFD Data 


\section{EXPERIMENTATION AND TESTING}

The prototype model is tested in a low speed wind tunnel available at IIAEM Jain University, with a test section of 600 x 600 x $2000 \mathrm{~mm}$ and maximum speed of $45 \mathrm{~m} / \mathrm{s}$. The three component balance which can measure a maximum Lift of $98.1 \mathrm{~N}$ and Drag of $19.62 \mathrm{~N}$ was used for force measurement. The flow visualisation of the baseline model was carried out using tufts to analyse the vortex generation.

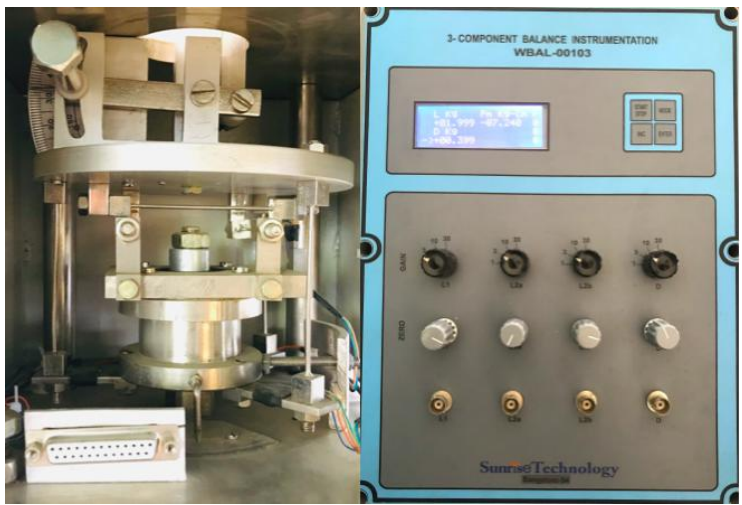

Figure 12: 3-Component balance setup

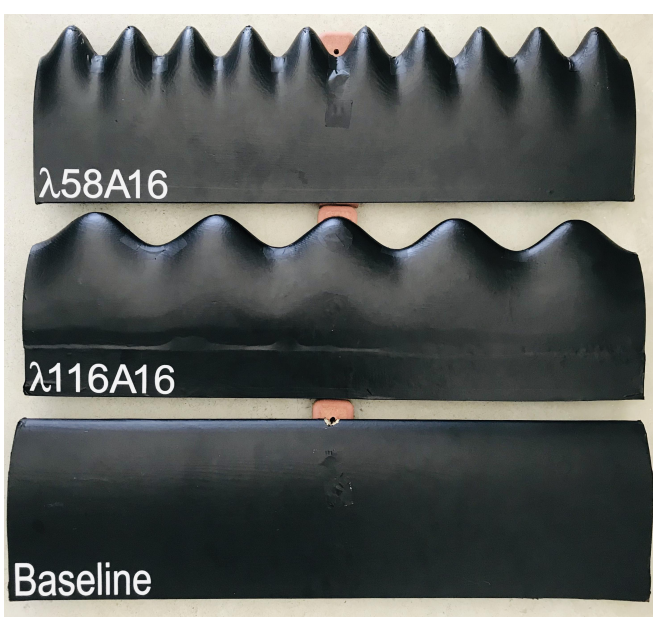

Figure 13: Fabricated wing models

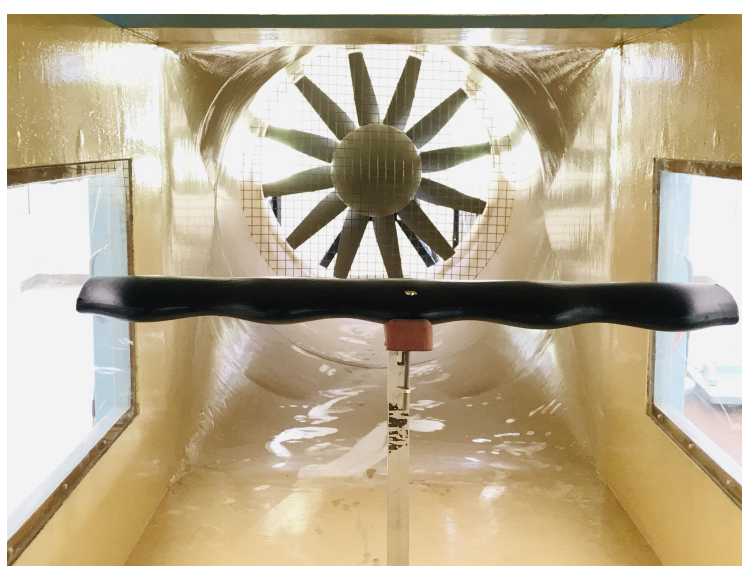

Figure 14: Wing model undergoing testing in Wind Tunnel

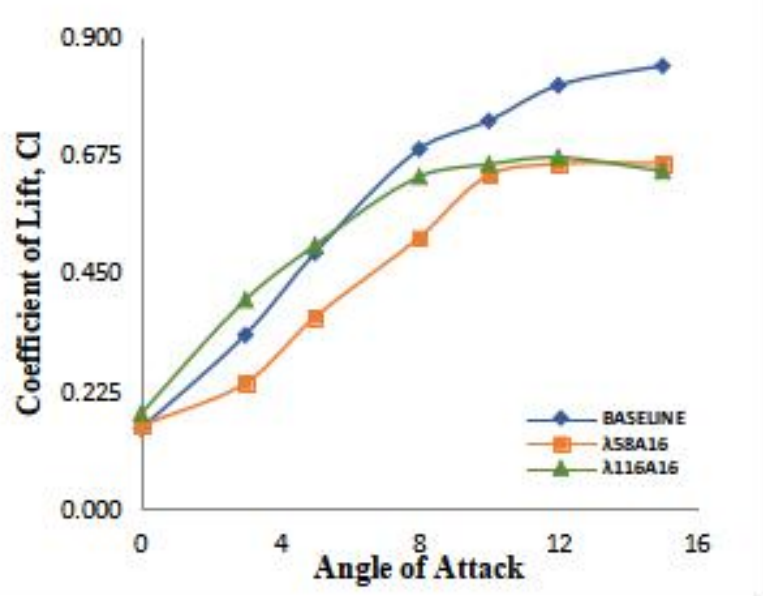

Figure 15: Comparison of $C_{1}$ vs Alpha from Wind Tunnel Data

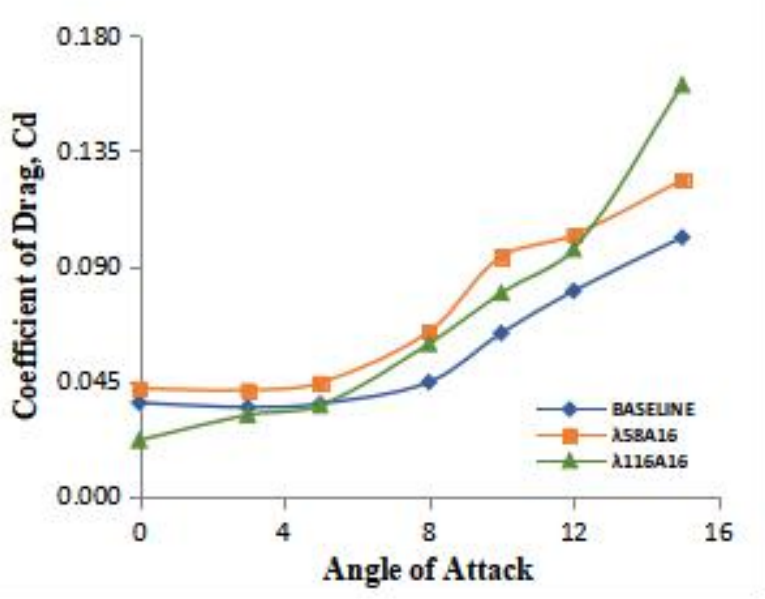

Fig 16: Comparison of $C_{d}$ vs Alpha from Wind Tunnel Data

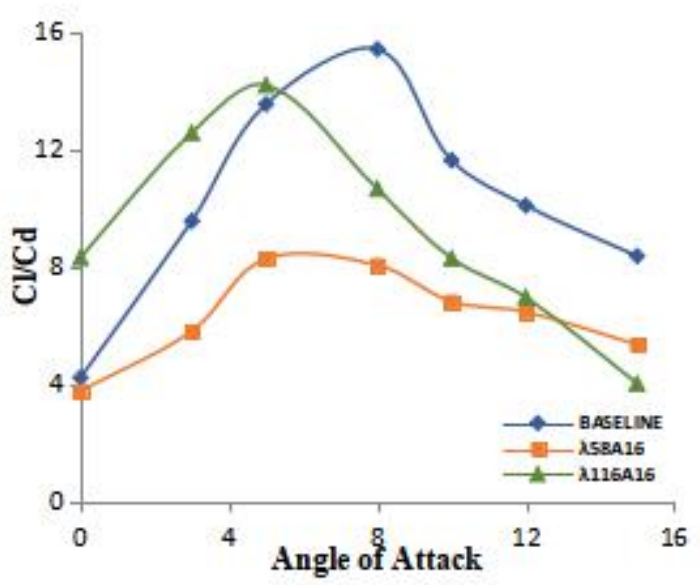

Figure 17: Comparison of $C_{1} / C_{d}$ vs Alpha from Wind Tunnel Data 


\section{RESULTS}

The Lift, Drag and Lift by Drag coefficients i.e., $\mathrm{C}_{\mathrm{l}}, \mathrm{C}_{\mathrm{d}}$, and $\mathrm{C}_{1} / \mathrm{C}_{\mathrm{d}}$ respectively are plotted against the angle of attack for Baseline, $\lambda 58 \mathrm{~A} 16$ and $\lambda 116 \mathrm{~A} 16$ models for both CFD and Wind Tunnel results to obtain a better understanding of behaviour of the models with and without tubercles.

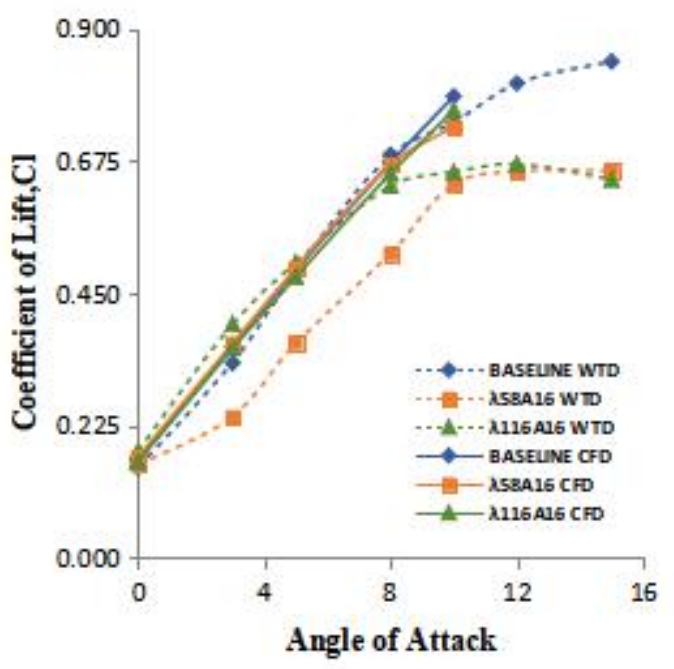

Figure 18: Comparison of $\mathrm{C}_{1}$ vs Alpha from Wind Tunnel and CFD Data

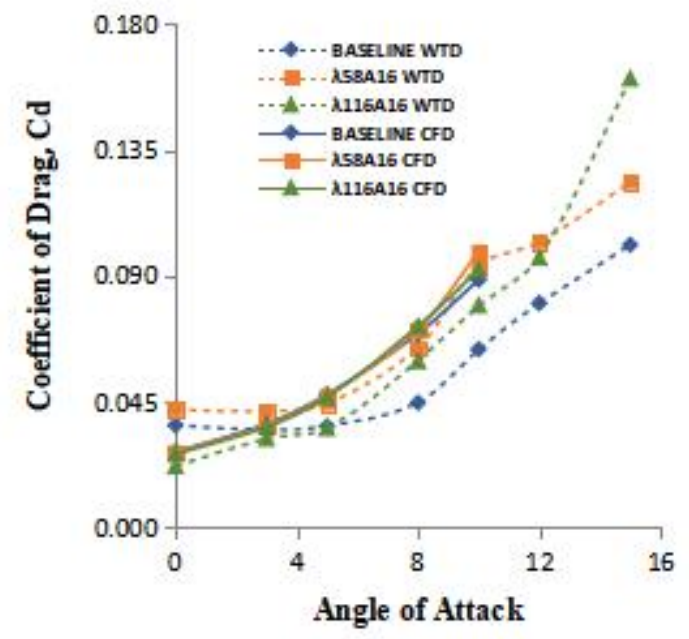

Figure 19: Comparison of $C_{d}$ vs Alpha from Wind Tunnel and CFD Data

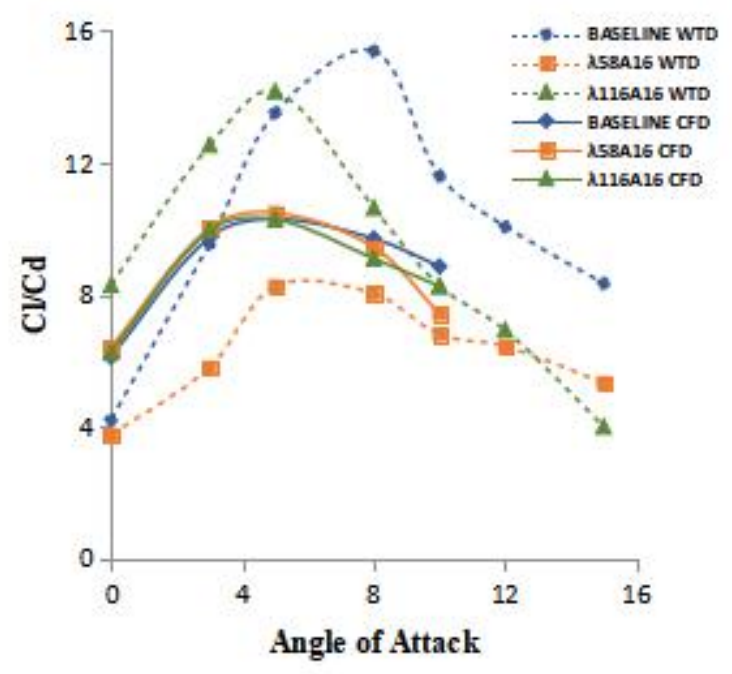

Figure 20: Comparison of $C_{1} / C_{d}$ vs Alpha from Wind Tunnel and CFD Data

The application of leading-edge tubercles for passive control of flow have potential applications in the design of control surfaces, wings, propellers, fans, and wind turbines etc.

\section{CONCLUSION}

In this report, the effect of Tubercles on the Lift and Drag performance has been investigated. It was found that the amplitude and wavelength of tubercle configurations were important parameters to consider when optimising performance. A suitable method by which to compare aerofoils with and without tubercles was through force measurements of Lift and Drag. For a Reynolds number of Re 200,000 the results for NACA634-421 with tubercles i.e., $\lambda 58 \mathrm{~A} 16$ and $\lambda 116 \mathrm{~A} 16$ were compared with the unmodified model. Following conclusion was obtained :

1. From the graph of $C_{1} / C_{d}$ vs Alpha from the Wind Tunnel Data, both $\lambda 58 \mathrm{~A} 16$ and $\lambda 116 \mathrm{~A} 16$ have higher $\mathrm{C}_{1} / \mathrm{C}_{\mathrm{d}}$ ratio at lower angle of attacks when compared with the Baseline model. But it can also be seen that as the angle of attack increases performance of the tubercle models deteriorates.

2. $C_{1}$ vs Alpha curve of Wind Tunnel data shows that model $\lambda 116 \mathrm{~A} 16$ has greater $\mathrm{C}_{1}$ at low angle of attacks and falls as the angle of attack increases.

3. Also, the same model has least $\mathrm{C}_{\mathrm{d}}$ for angle of attack $<5$ degree. But above 5 degree, the slope of the curve increases drastically leading to higher $\mathrm{C}_{\mathrm{d}}$ i.e., higher Drag.

4. From the CFD data model $\lambda 58 \mathrm{~A} 16$ was observed to have greater $\mathrm{C}_{1}$ when compared to the other models. Also it is observed to have lower $\mathrm{C}_{\mathrm{d}}$.

It is important to note that the performance of the models can vary with Reynolds number. It is noted from already published papers that the performance of a wing with tubercles has higher performance at greater Reynolds number $(>500,000)$ and decreased performance with lower Reynolds number $(<500,000)$. Here, the Reynolds number for which the test was carried out is 200,000 due to the limitation of the wind tunnel being low speed. 
In our present study, we have only used k- $\omega$ SST as turbulence model and based on previous papers on the same, it is not capable of capturing separation bubble. Therefore, CFD model can be refined more with respect to turbulence model and may also with respect to convergence etc.

\section{ACKNOWLEDGMENTS}

We immensely thank Prof. Ashish Gupta, Professor of Aerospace Engineering, IIAEM - Jain University \& Dr. P A Aswatha Narayana, Retd. Professor of Aerospace Engineering, IIT-Madras in providing us with the right instructions and guidance through the course of this work.

We would like to extend our gratitude to the honourable Chancellor of Jain University, Dr. C G Krishnadas Nair, Former Hindustan Aeronautics Limited Chairman and a top aerospace scientist for his constant encouragement to carry out this research work.

We would like to thank Mr. Velayudam $M$ for his keen assistance in experimentation analysis at IIAEM - Jain University

We would also like to express our sincere gratitude to Prof. Dr. Antonio Davis, Director, IIAEM - Jain University for his constant encouragement and providing the necessary facilities.

\section{REFERENCES}

1. Frank E. Fish, Paul W. Weber, Mark M. Murray and Laurens E. Howle - "The Tubercles on Humpback Whales Flippers: Application of Bio-Inspired Technology."

2. Kristy Lee Hansen - "Effect of leading edge tubercles on airfoil performance."

3. Derrick Custodio - "The Effect of Humpback Whale-like Leading Edge Protuberances on Hydrofoil Performance."

4. P. Watts F. E. Fish - “ The influence of passive, leading edge tubercles on wing performance."

5. Anderson, J. D. (1991). Fundamentals of aerodynamics. McGraw-Hill.

6. D. Serson, J. R. Meneghini - “Numerical study of wings with wavy leading and trailing edges."
7. K L Hansen, R M Kelso and B B Dally - "An investigation of Three-Dimensional effects on the performance of tubercles at low Reynolds numbers"

8. Katz \& Plotkin - "Low Speed Aerodynamics, From wing theory to panel methods." Cam- bridge University Press, $2^{\text {nd }}$ Ed., 2001.

9. Andr' e Deperrois - "Illustration of the use of Control Polar s in XFLR5 Presentation document." July 2008, http://xflr5 .sourceforge.net/docs/Control_analysis. pdf.

10. Menter, F.R. - "Zonal Two Equation k- $\omega$ Turbulence Models for Aerodynamic Flows", AIAA Paper 93-2906, 1993.

11. Bardina, J.E., Huang, P.G. and Coakley, T.J., "Turbulence Modeling, Validation, Testing and Development," NASA Technical Memorandum 110446, 1997. 